\title{
Desinstifucionalização e Renovação no Ensino Superior
}

\author{
Tristan McCowan' \\ 'University College London (UCL), Londres - Reino Unido
}

\begin{abstract}
RESUMO - Desinstitucionalização e Renovação no Ensino Superior. Apesar de alguma heterogeneidade superficial, as instituições de ensino superior do mundo inteiro compartilham algumas estruturas centrais. De acordo com críticos como Ivan Illich, a ossificação destas formas institucionais terminou empobrecendo as práticas que originalmente pretendiam apoiar. Este artigo avalia as bases para essas afirmativas e a construção associada de alternativas. Identifica três aspectos significativos da instituição: portas de entrada - os controles sobre as admissões à universidade; funções - as diferenciações entre estudantes, docentes e outros atores; e carimbos - os processos e os artefatos de validação da aprendizagem e do conhecimento adquirido pelo estudante. Estes três aspectos se apresentam em diferentes formas, níveis de rigidez e pontos de controle, tendo impactos dúbios sobre a igualdade e a justiça social e sobre o propósito central da universidade de promover a compreensão humana. São apresentadas implicações para o futuro da universidade e para as atuais iniciativas que estão tentando subverter estas estruturas e criar modelos alternativos.

Palavras-chave: Ensino Superior. Desescolarização. Reforma da Universidade.
\end{abstract}

ABSTRACT - Deinstitutionalisation and Renewal in Higher Education. Despite some superficial heterogeneity, higher education institutions around the world share core structures. According to critics such as Ivan Illich, the ossification of these institutional forms has ended up impoverishing the practices they were originally intended to support. This article assesses the grounds for these claims and associated construction of alternatives. It identifies three significant features of the institution: gates the controls on admissions to the university; roles - the distinctions drawn between students, lecturers and other actors; and badges - the processes and artefacts of validation of student learning and scholarship. These three features are seen to have varying forms, levels of rigidity and loci of control, and have ambiguous impacts on equality and fairness, and on the core purpose of the university to promote human understanding. Implications are drawn out for the future of the university, and for current initiatives that are attempting to subvert these structures and create alternative models. Keywords: Higher Education. Deschooling. University Reform.

Educação \& Realidade, Porto Alegre, v. 46, n. 4, e117607, 2021. 
Desinstitucionalização e Renovação no Ensino Superior

\section{Introdução}

Nos últimos anos, o ensino superior tem sido foco de inúmeros esforços de reforma no mundo inteiro. Estas tentativas se dirigem não apenas ao nível sistêmico (mercantilização, financiamento estudantil, ingresso de novos fornecedores), mas também à própria instituição, sua governança e seu modelo e práticas educacionais. As reformas em comum incluíram a promoção de habilidades genéricas para empregabilidade e empreendedorismo; a introdução do ensino à distância e híbrido; o uso de tecnologias na oferta presencial; a ampliação da participação e das ações afirmativas; as mudanças em estruturas departamentais e a criação de unidades interdisciplinares; e os movimentos rumo à sustentabilidade ambiental (Crow; Dabars, 2015; Laurillard; Kennedy, 2017; Mason et al., 2006; McCowan; Leal Filho; Brandli, 2021; Norões; Costa, 2012; Williamson, 2018).

Essas mudanças têm sido mais notáveis em alguns contextos do que em outros; por exemplo, as reformas neoliberais trazem mudanças significativas na orientação e no funcionamento da universidade em países anglófonos. No entanto, mesmo nestes casos, a instituição ainda é reconhecível desde suas primeiras manifestações e identificável com suas contrapartidas que remontam ao período medieval não apenas no nome, mas também em suas características centrais. A resiliência da universidade é marcante em termos de suas estruturas, práticas e rituais, e poucas das reformas acima mencionadas desacomodaram estes padrões subjacentes. Além disso, embora haja características nacionais e regionais evidentes em termos de política de ensino superior e alguns autores identifiquem modelos distintos - por exemplo, o latino-americano (Bernasconi, 2007), o confuciano (Marginson, 2014) ou o nórdico (Välimaa, 2018) - existe um marcado nível de homogeneidade no ensino superior em termos globais. Entre as várias tradições diferentes de ensino superior nos tempos antigos, apenas as instituições islâmicas permanecem de maneira intacta até os dias de hoje, sendo que a maior parte das instituições no mundo são adaptações do modelo europeu.

As razões para o predomínio de determinada forma institucional no ensino superior são numerosas e complexas, envolvendo questões históricas em termos de geopolítica, colonização e soft power, além de processos continuados de globalização, dependência, expansão de mercados, e avanços em transporte e em tecnologia de informação e de comunicação. Também existe um conjunto distinto de questões acerca da relevância dessa homogeneidade e continuidade para o funcionamento e o impacto da universidade. A manutenção de estruturas tradicionais como procedimentos de admissão, agrupamentos por ano, divisões disciplinares, hierarquias docente-discente e colação de grau é necessária ou até mesmo essencial para o alcance de seus objetivos ou, alternativamente, são grilhões que a aprisionam?

Este artigo explora estas questões sobre a natureza das estruturas institucionais que sustentam a universidade e sua importância em termos morais, políticos e educacionais. Em primeiro lugar, identificar de 
maneira imediata as estruturas não é uma tarefa fácil, dado o profundo arraigamento que as tornou quase invisíveis para aquelas pessoas educadas no sistema. Então, a primeira tarefa é tornar estranho o familiar. A segunda é determinar suas funções e seu impacto em relação aos propósitos da universidade. São posicionamentos coerentes nem manter as estruturas institucionais tradicionais da universidade simplesmente por serem tradicionais nem as rejeitar pelo mesmo motivo. Precisamos de uma avaliação da função que desempenham - na teoria e na prática. Por fim, e como uma extensão da segunda tarefa, o artigo explora o que ocorre quando as estruturas são removidas, com base em alguns exemplos ilustrativos de iniciativas de desescolarização em prática.

Ao determinar a viabilidade e a desejabilidade desse processo de desinstitucionalização, a pergunta que inevitavelmente é feita é qual parâmetro estamos usando para julgar a universidade. É extremamente difícil fornecer definições da instituição. Este artigo será embasado em um pressuposto de que o propósito central da universidade é, nas palavras de Collini (2012, p. 92), "ampliar a compreensão humana por meio da pesquisa aberta”, com a coesão da organização e das atividades da instituição em torno dessa finalidade. Poderíamos acrescentar a esta definição que a universidade é diferente de outras formas educacionais por proporcionar o estudo em profundidade, sendo sustentada em determinadas áreas do conhecimento, ao invés de uma educação simples, genérica ou em curto prazo.

Uma análise anterior da função do ensino superior para alcançar os Objetivos de Desenvolvimento Sustentável (McCowan, 2019) explorou a ideia da 'universidade pós-desenvolvimento', aquela que poderia abrir novas possibilidades além do atual desenvolvimento compacto com suas boas intenções, mas armadilhas problemáticas de modernidade, capitalismo e colonialidade. Considerava-se que a universidade pós-desenvolvimento continha dois elementos: ecologia de saberes e desinstitucionalização ${ }^{1}$. O primeiro deles tem recebido muita atenção na literatura e em movimentos sociais e políticos. Manifesta-se especificamente em clamores por decolonização do currículo, com uma longa história na América Latina, mas que vieram à tona nos últimos anos por meio dos protestos Rhodes Must Fall na África do Sul ${ }^{2}$. A relevância da decolonização é mais óbvia em países colonizados recentemente que - apesar da independência formal e da emergência de um sistema de ensino superior autônomo - ainda mantêm a antiga influência colonial em seu conteúdo curricular, na seleção de disciplinas, nas listas de leitura, nos fundamentos epistêmicos e, às vezes, no corpo docente (Del Monte; Posholi, 2021; Heleta, 2016; Mbembe, 2016). No entanto, estes movimentos também se difundiram para os sistemas de ensino superior dos antigos poderes coloniais, buscando diversificar o currículo no contexto de populações multiétnicas e corpo discente internacional diversificado.

Estes escritos e movimentos se concentram fundamentalmente na crítica àquilo que precisa ser removido da universidade (a derrubada da estátua). Em termos daquilo que poderia substitui-la, há clamores 
Desinstitucionalização e Renovação no Ensino Superior

pela indigenização do currículo - em níveis crescentes de profundidade a partir dos fatos e do conteúdo de disciplinas até a teoria e a visão de mundo - ou por um pluralismo, ecologia ou diversidade de variadas formas de conhecimento. A ideia do pluralismo epistêmico e epistemologias do Sul vem recebendo mais atenção nos últimos anos (Arora; Stirling, 2020; Connell, 2014; Cortina; Earl, 2020; Takayama; Sriprakash; Connell, 2015; Santos, 2015; Unesco, 2021), embora seja mais frequentemente seguida em termos bem gerais. Também existem alguns exemplos em prática, como as universidades interculturais no México, que objetivam proporcionar um espaço para o ensino superior em saberes, tradições e idiomas indígenas, em diálogo com o conhecimento acadêmico convencional, levando a cursos de graduação formalmente reconhecidos em pé de igualdade com outras instituições (Dietz, 2009; Perales Franco; McCowan, 2021; Schmelkes, 2009).

Entretanto, o segundo aspecto - desinstitucionalização - tem recebido muito menos atenção, tanto na literatura como na prática. Muito dos escritos e da mobilização em torno da decolonização supõe que as estruturas da universidade, do sistema de ensino superior e do sistema global de conhecimento permanecerão, em grande parte, embora com diferentes conteúdos de conhecimento e diferentes vozes, com uma redistribuição de oportunidades para falar e escutar dentro destes sistemas. Boaventura de Sousa Santos, um dos escritores mais prolíficos sobre este tema, reconhece a necessidade de desafiar formas institucionais ao implantar a ecologia dos saberes:

\begin{abstract}
Por universidade polifônica eu quero dizer uma universidade que exercita seu compromisso de forma plural, não só em termos de conteúdo substancial, mas também em termos institucionais e organizacionais. Uma universidade polifônica é uma universidade cuja voz comprometida é composta não somente por muitas vozes, mas é, acima de tudo, composta por vozes que são expressas por meio de duas formas - convencional e não convencional em processos de aprendizado orientados por diploma ou não orientados por diploma (Santos, 2018, p. 277).
\end{abstract}

Santos $(2017 ; 2018)$ propõe as noções da pluriversidade e da subversidade: a primeira se refere à transformação dentro do sistema, enquanto a última se refere a fora dele. A pluriversidade é caracterizada por dois elementos: compromisso com a justiça social e uma ecologia de saberes, sendo mais plural do que unitária (como a universidade é) em termos de sua base epistêmica, currículo e comunidade. Um exemplo deste tipo de instituição é a Universidade da Integração Internacional da Lusofonia Afro-Brasileira (Unilab) no nordeste do Brasil. Foi fundada em 2010 para ser um centro para cooperação Sul-Sul entre o Brasil e os países africanos falantes de português, bem como um ponto focal para ensino e pesquisa relacionados com as culturas africanas no Brasil. Embora possua elementos particulares, a Unilab é uma universidade federal e adere às estruturas padrão de admissão, composição do corpo docente, currículo e qualificações do sistema federal. Como muitas destas 
inovações, a Unilab não tem conseguido alcançar todos os objetivos pretendidos, em parte devido à mudança de governo de 2016 no Brasil e à ativa hostilidade do Estado, do qual depende para financiamento e regulação.

A subversidade, por outro lado, opera fora do sistema de ensino superior, em geral sem reconhecimento formal nem fontes de financiamento, apresentando práticas de ensino e pesquisa que muitas vezes não são reconhecíveis por aquilo que é convencional. Na visão de Santos (2018, p. 277), o termo subversidade "captura tanto o caráter subalterno de grupos sociais muitas vezes envolvidos em suas iniciativas como a maneira subversiva como intervém na ideia da universidade convencional". Embora os exemplos de subversidade em prática não sejam proeminentes, em parte devido ao tamanho geralmente pequeno e à transitoriedade destas iniciativas, existem várias experiências como essa em todas as regiões do mundo, muitas delas membros da Aliança de Ecoversidades. Estão incluídas a Unitierra no México e a Swaraj na Índia, que serão delineadas em maiores detalhes a seguir, iniciativas que são um desafio consciente à nossa noção de universidade ao eliminarem requisitos para admissão, a certificação, a diferenciação entre docentes e discentes e os programas de estudo.

Estas ideias são importantes ao atrair nossa atenção para a necessidade tanto de contestar como transformar as instituições convencionais existentes, além de abrir espaço para a criação de novas formas de instituição. Contudo, é necessário analisar mais as estruturas da universidade que devem ser subvertidas. Este artigo assume esta tarefa ao proporcionar um mapeamento teórico das características institucionais importantes, e evidencia as implicações de seu abandono ou substituição.

\section{Institucionalização e desinstitucionalização}

As instituições foram definidas como:

$$
\begin{aligned}
& \text { [...] um complexo de cargos, funções, normas e valores } \\
& \text { alojados em determinados tipos de estruturas sociais e } \\
& \text { organizando padrões relativamente estáveis de atividade } \\
& \text { humana no que tange a problemas fundamentais ao pro- } \\
& \text { duzir recursos que sustentam a vida, reproduzir indiví- } \\
& \text { duos e sustentar estruturas societais viáveis em um dado } \\
& \text { ambiente (Turner, 1997, p. 6). }
\end{aligned}
$$

As instituições podem assumir duas formas gerais: organizações formais ou normas sociais. Assim, podemos descrever a igreja católica ou o parlamento ou as prisões como instituições, tanto quanto o casamento, a família ou o patriarcado. Neste estudo, o termo será usado fundamentalmente no sentido de uma organização formal, apesar de ter sua base tanto em um conjunto de ideias e práticas quanto em um modelo organizacional específico.

A literatura sobre a função das instituições na sociedade é extensa e em várias disciplinas diferentes, incluindo a sociologia, a economia e 
Desinstitucionalização e Renovação no Ensino Superior

a antropologia (Acemoglu et al., 2005; DiMaggio; Powell, 1983; North, 1990; Scott, 2013). No campo da educação, o neoinstitucionalismo tem sido uma importante corrente na sociologia da educação e na educação comparada, particularmente associada à Stanford University (Baker; LeTendre, 2005; Benavot; Riddle, 1988; Chabbott, 2002; Meyer et al., 1977). Um foco importante desta pesquisa foi a expansão da educação em massa no mundo inteiro, bem como a convergência entre sistemas nacionais diferentes e a adoção de políticas e currículos semelhantes, associada à teoria da cultura mundial (Meyer; Rowan, 2006; Anderson Levitt, 2003). Nas últimas décadas, tem havido debates vigorosos a respeito da existência ou não de uniformidade ou diversidade, convergência ou divergência de escolas e sistemas educacionais no mundo (Silova; Rappleye, 2015).

Em estudos do ensino superior, a teoria institucional tem sido usada para compreender as tendências isomórficas e a 'deriva acadêmica' entre universidades, pois as instituições se tornam mais parecidas com suas congêneres mais conceituadas, desenvolvendo cursos de pósgraduação e programas de pesquisa em sua busca por legitimidade e reconhecimento público (Morphew; Huisman, 2002). DiMaggio e Powell (1983) defendem que essa homogeneidade é causada por três forças: coerciva (pressão feita por outras organizações das quais a instituição é dependente, especialmente do governo), mimética (emulação de organizações mais conceituadas) e normativa (por meio de redes profissionais e comunicação). Em alguns casos, a regulação governamental busca frear estes processos de isomorfismo, enquanto outras vezes os impulsiona - por exemplo, a diferenciação entre universidades e institutos politécnicos foi dissolvida no Reino Unido em 1992.

Na contemporaneidade, a internacionalização e os ranqueamentos são centrais na busca por legitimidade, pois as instituições procuram reconhecimento por meio da adesão a organizações, parcerias e alta posição em tabelas nacionais, regionais ou internacionais. No entanto, nem todos os estudiosos concordam que a busca por legitimidade entre as universidades está levando a uma completa homogeneização: Stensaker et al. (2019), por exemplo, em seu estudo dos planos estratégicos das instituições, defendem que, ao contrário, estamos rumando para a estratificação, pois diferentes escalões dos sistemas aspiram a diferentes níveis, sendo que alguns constroem o reconhecimento por meio de impacto local, ao invés de ser 'classe mundial'. Zapp, Jungblut e Ramirez (2020) demonstram que, embora a adesão a organizações como a International Association of Universities possa conferir legitimidade a alguns tipos de universidade, as instituições no topo da classificação têm pouca necessidade e podem se basear em sua posição no ranqueamento e em grupos de adesão menores, exclusivos.

A literatura sobre teoria institucional no ensino superior ajuda a explicar por que é tão difícil as instituições escaparem do molde convencional. Conforme foi esboçado acima, as instituições educacionais podem ser consideradas como 'organizações institucionais' em vez de ‘organizações técnicas’ (Meyer; Rowan, 2006). Diferentemente das 
últimas, que operam com base na eficiência, usando tecnologias bem definidas para produzir resultados facilmente medidos, as primeiras "utilizam tecnologias dúbias (por exemplo, docência) para gerar produtos (por exemplo, conhecimento, estudantes muito capacitados) cujo 'valor' e 'qualidade' são muito difíceis de determinar" (Morphew; Huisman, 2002, p. 495). De acordo com os autores, isto leva à "aquisição de práticas e estruturas definidas normativamente", pois "uma faculdade é uma faculdade apenas quando aqueles dentro e fora da organização a veem como uma versão legítima dela” (p. 496). Estas considerações nos ajudam a compreender como é difícil criar universidades alternativas ou promover mais do que reformas superficiais na instituição.

Embora ciente dessa literatura, este artigo aborda um conjunto muito diferente de questões sobre a institucionalização. Em vez da pergunta empírica de como as instituições surgem, se desenvolvem e cessam de existir, por que aparecem em determinados contextos e não em outros ou se manifestam de diferentes maneiras, está voltado para a questão normativa se deveríamos procurar ativamente desmontar e reconstruir a instituição universidade. É claro que esta tarefa envolve uma análise da maneira como a instituição universidade é atualmente - isso será esboçado na seção a seguir, apesar de enfatizar elementos fundamentais de sua estrutura sem uma análise histórica ou comparativa extensa de seu surgimento em contextos específicos.

A hipótese proposta a ser explorada neste artigo é apresentada por Ivan Illich $(1971 ; 1973 ; 1975)$ em suas análises de várias instituições da modernidade: que a institucionalização é uma parte bem-motivada e talvez inevitável da maneira como as sociedades se desenvolvem para proteger e promover práticas caras a ela - seja saúde, educação, devoção religiosa, relacionamentos ou criação de filhos. Mesmo assim, as estruturas desenvolvidas para oferecer e proteger, fornecer recursos e regular, com o tempo superam seu necessário tamanho e alcance, se ossificam e assumem importância por mérito próprio, ao invés de atender ao bem original em questão. Neste estágio, as instituições começam a solapar e até mesmo destruir aquele bem - o princípio da contraprodutividade (Smith, 2011, p. 5)

Tanto os ricos como os pobres dependem das escolas e dos hospitais que orientam suas vidas, formam sua visão de mundo e a definem para elas o que é legítimo e o que não é. Ambos consideram tratar a si mesmo como irresponsável, aprender por si como duvidoso e a organização comunitária, quando não paga por aqueles com autoridade, uma forma de agressão ou subversão. Para ambos os grupos, a confiança no tratamento institucional resulta em suspeita acerca de realizações independentes.

Assim, para Illich, existe uma função incapacitante das instituições ao oferecerem a ilusão da realização pelo tratamento e, simultaneamente, prejudicar as habilidades das pessoas de aprenderem por si e mutuamente no cotidiano. O objetivo é o que ele denomina aprendizagem 'em convivência', livre de tecnologias e controle desumanizadores, 
Desinstitucionalização e Renovação no Ensino Superior

ou "redes educacionais que intensificam a oportunidade para cada um transformar cada momento de sua vida em um momento de aprendizagem, compartilhamento e cuidado" (Illich, 1971, p. 2).

A crítica de Illich à educação tem várias dimensões (Smith, 2011). Algumas são razoavelmente comuns em comentários críticos sobre educação, como a rejeição à comodificação. Também existe o currículo oculto, as mensagens perniciosas transmitidas pelas culturas da escolarização que permeiam e empobrecem nossas vidas: para Illich, são notáveis entre elas a indução ao consumismo, a criação de dependência das instituições e a naturalização das desigualdades. Segue-se a super ênfase sobre as qualificações, a priorização das avaliações formais da aprendizagem ao invés da aprendizagem em si pelos professores, estudantes e todas as demais partes interessadas - discutida em outra publicação como a doença do diploma (Dore, 1976). Porém, há dois outros pontos que são mais peculiares para Illich. Embora as críticas e as reformulações da função do professor sejam lugar comum, Illich vai adiante ao afirmar que a própria existência de professores profissionais é um problema. Ele defende que, para que haja aprendizagem em todos os espaços de nossas vidas, precisamos nos distanciar da ideia de que a função do ensino está confinada a alguns especialistas. Ao contrário, todas as pessoas são professores e todas são educandos. Por fim, existe a análise do sistema educacional como um ciclo de autoperpetuação. Apesar dos óbvios inconvenientes do nosso sistema educacional corrente à luz dos elementos acima, ele se reproduz continuamente rumo ao futuro, pois suas garras estão profundamente enterradas em nossas sociedades. Como na maioria dos países a subsistência e até mesmo a sobrevivência depende em grande medida de qualificações educacionais formais, simplesmente abandoná-las não é uma opção para a maioria das pessoas.

As ideias de Illich a respeito da desescolarização foram desenvolvidas juntamente com seu colega no Centro Intercultural de Documentación (CIDOC) no México, Everett Reimer, que publicou sua própria versão em School is Dead (Reimer, 1971), e levadas adiante por diversos pensadores e ativistas contemporâneos como Gustavo Esteva, Manish Jain e Madhu Suri Prakash. Ironicamente, a efetivação mais proeminente das ideias de desescolarização se deu por aqueles que se opunham às opiniões políticas de Illich, os libertários do livre mercado, não os anarcocomunistas. Cada vez há mais exemplos daquilo que foi chamado de ‘desescolarização do Vale do Silício’ (McCowan, 2016) e ‘desescolarização de cima para baixo' (Sukarieh; Tannock, 2020), criticando a educação formal por sua inadequação para formar empresários e forjar oportunidades no mercado capitalista. Iniciativas como Uncollege e Thiel Fellowships seguem esta linha.

A crítica mais geral de Illich às instituições não é livre de controvérsia nem contestação. Os questionamentos se a religião organizada promove a espiritualidade ou, ao contrário, a reprime, sobre os efeitos do nosso sistema policial e de justiça criminal na ordem pública, e das práticas médicas contemporâneas sobre nossa saúde e bem-estar não 
estão resolvidos, são altamente politizados e não são suscetíveis a testes empíricos simples. Do mesmo modo, questões sobre a desescolarização são perturbadoras e emocionais e têm mais detratores do que proponentes. Ao reconhecer as complexidades e os riscos da desescolarização, este artigo assume como ponto de partida que a reavaliação radical (no sentido de ir às raízes) de instituições educacionais é valiosa e certamente essencial, e que não deveríamos considerar nenhum aspecto das estruturas tradicionais como garantido.

O parágrafo acima propõe suposições sobre instituições e experiências compartilhadas que podem ser injustificadas. As instituições diferem dependendo do contexto e funcionam de maneira diferente em relação a populações diversificadas em determinado contexto. Assim, o sistema judiciário pode, ao mesmo tempo, ser altamente eficaz para os poucos privilegiados e pernicioso para os grupos marginalizados. Com isso, a análise feita neste artigo das implicações das instituições educacionais deve distinguir os grupos na sociedade - e é impossível ignorar a estratificação dos resultados na educação. No entanto, este artigo não se restringe a uma análise das desigualdades na e por meio da educação, e continua aberto à possibilidade, levantada por Illich, dos impactos negativos da educação institucional sobre todos os educandos.

Embora Illich explore em profundidade alguns aspectos da escolarização - a função do professor e do currículo oculto -, há outros aspectos importantes da estrutura da instituição que não são tratados diretamente e precisam ser analisados. Este artigo faz esta avaliação por meio de três facetas - portas de entrada, funções e carimbos, conforme será delineado a seguir. A análise está baseada nos insights fundamentais de Illich e, apesar de não aderir a cada aspecto de seu argumento ou endossar todas suas afirmativas empíricas em Deschooling Society, apoia o princípio central de que a dependência das instituições pela humanidade precisa ser questionada e que precisamos sair da desumanização e rumar para as relações de convivência. No entanto, é possível considerar que as universidades possuem algumas características distintivas em relação às escolas que são foco da análise de Illich. As universidades têm uma multiplicidade de funções além da educação, sendo a mais importante a pesquisa, que podem manifestar elementos de institucionalização, mas de maneiras distintas. Outra diferença importante é a autonomia muito maior das universidades. Muito da crítica de Illich está relacionada ao controle tecnocrático, e nas universidades existe uma maior proporção de controle pelos profissionais (a comunidade acadêmica) - embora assumidamente menor na era neoliberal.

\section{Portas de Entrada, Funções e Carimbos}

A análise apresentada neste artigo enfoca três características: portas de entrada, funções e carimbos. As portas de entrada se referem aos mecanismos da universidade que determinam o que entra, e em uma menor medida, o que sai, protegidas por controladores. O mais óbvio deles é o processo para selecionar quais estudantes podem ser 
Desinstitucionalização e Renovação no Ensino Superior

admitidos. As funções se referem aos papeis que diferentes atores desempenham na universidade, a diferenciação entre professores e estudantes, entre corpo acadêmico e funcional e as hierarquias em todas as categorias. Por fim, os carimbos se referem à validação que é fornecida aos produtos da universidade: particularmente, o aprendizado dos estudantes que se graduam e a qualidade das publicações acadêmicas.

Embora não representem um quadro abrangente da universidade (e diversos aspectos de governança, aprendizagem e envolvimento societal precisariam ser abordados em separado), estes três elementos constituem características fundamentais e são alvos proeminentes da desinstitucionalização. Conforme será observado na análise abaixo, os três têm implicações importantes na prática relacionada tanto com a finalidade central da universidade de promover a compreensão humana como a justiça social. Funcionam diretamente como mecanismos de inclusão e exclusão de pessoas e para facilitar e restringir o que é possível em termos de prática. Porém, também atuam indiretamente para dar forma a entendimentos dos processos de aprendizagem e de conhecimento adquirido, de maneira similar ao 'currículo oculto'.

\section{Portas de entrada}

As universidades estão necessariamente envolvidas em intercâmbio com a sociedade mais ampla. Em um estudo anterior (McCowan, 2019), este fluxo foi capturado pela noção de interação, como uma integrante da tríade de características da universidade, juntamente com valor e função. A interação com a sociedade ocorre através de uma membrana semipermeável, envolvendo um movimento interno e externo de atores e ideias. As universidades variam na facilidade como este movimento interno e externo ocorre. Assim, as universidades da Ivy League restringem muito o ingresso de atores, enquanto é fácil o acesso a distância às universidades de desenvolvimento ou cívicas, que desempenham um ativo papel no desenvolvimento local, terão mais movimentação externa de ideias do que as universidades tradicionais, concentradas em pesquisa básica.

Esta interação é mediada por portas de entrada, que determinam o que entra e sai da instituição e, desse modo, controlam em grande medida a natureza e a percepção da universidade. As portas de entrada são operadas por controladores seja na forma de atores humanos com julgamentos arbitrários ou de procedimentos ou algoritmos formulados em textos e programas. Os controladores podem operar de uma maneira idiossincrática ou por motivação pessoal, mas em grande medida refletem a missão e o sentido de eu da instituição como um todo. Qualidade e status são os impulsionadores dominantes para os controladores na academia.

A admissão dos estudantes representa a forma mais óbvia de porta de ingresso no ensino superior. Raramente os sistemas de ensino superior operaram sobre uma base universalista, admitindo o todo da coorte etária, e nos casos em que se aproximam disso, instituições es- 
pecíficas - as mais conceituadas - ainda fazem uma cuidadosa seleção dos estudantes. Existe uma ampla variedade de práticas relacionadas a critérios de admissão - em geral envolvem o desempenho em testes acadêmicos, seja avaliações ao fim do ensino médio ou exames específicos da universidade, ou às vezes experiência mais ampla de vida ou desempenho em entrevista - adotadas para selecionar os 'melhores' estudantes para a instituição. Embora muitos países tenham adotado políticas de ações afirmativas para se resguardarem contra a discriminação de determinados grupos da sociedade ou para promoverem ativamente seu acesso, a maior parte das portas de entrada serve para manter de fora aqueles com escores acadêmicos mais baixos, determinados em grande parte pela qualidade da escolarização prévia e, por conseguinte, vinculados à origem socioeconômica.

As portas de acesso podem ser justificadas de diferentes maneiras. Podem estar baseadas em um critério mínimo de qualidade. Assim, pode ser considerado necessário que os estudantes tenham um nível mínimo de habilidade acadêmica ou desempenho prévio para continuar os estudos na universidade. Mesmo assim, muitas vezes é discutido que este tipo de porta de entrada é necessário para defender a integridade acadêmica da instituição, e que abrir mais a porta de entrada levará a uma perda de padrões (de fato, este argumento tem sido mobilizado com grande efeito para manter a natureza elitista do ensino durante os últimos séculos). Não é possível aqui responder por completo ao complexo questionamento sobre quem deveria ou não ir para a universidade. Mas é suficiente dizer que restringir o acesso à universidade a poucos não tem nenhuma justificativa em si. A única limitação justa e coerente no acesso pode ser pelo fato de os estudantes se beneficiarem mais com o estudo universitário quando alcançarem um nível mínimo de preparação (McCowan, 2007). Mas se essa preparação puder ser oferecida na instituição (como o é em algumas ações afirmativas e estratégias de ampliação da participação), então nem mesmo este obstáculo é necessário.

Há outras formas de porta de entrada e de controle em operação nas universidades. As políticas de recrutamento de professores também atuam como filtro ao permitir o ingresso de determinados tipos de indivíduos e manter outros fora. Nas últimas décadas, o doutorado emergiu como critério básico para um cargo na academia, suplementado por diversos outros fatores, incluindo publicações e projetos de pesquisa, desempenho em entrevista, conexões e, em alguns casos, 'linhagem' (por exemplo, o orientador do doutorando). As portas de entrada podem operar não apenas em termos de entrada e saída de atores, mas também como formas de relacionamento com órgãos externos. Para as universidades de elite, as parcerias institucionais são uma área importante, e os interesses vinculados à identidade visual e ao prestígio da instituição irão significar que apenas alguns parceiros são considerados apropriados. O controle também pode operar em termos de movimento interno e externo de ideias, com algumas instituições assumindo uma cuidadosa curadoria das produções e mensagens que emanam da universidade. 
Desinstitucionalização e Renovação no Ensino Superior

O impacto óbvio das portas de entrada está em seu racionamento de oportunidades e em sua função na reprodução de desigualdades socioeconômicas. Embora as universidades possam não ter a intenção de aplicar critérios que discriminem comunidades de baixa renda ou aquelas de grupos de idioma, racial, étnico, gênero ou classe social marginalizados, na maior parte dos casos elas o fazem. As portas de entrada também podem levar à homogeneidade de atores se os mesmos critérios forem sempre aplicados e podem agir contra os benefícios positivos da diversidade.

\section{Funções}

O segundo mecanismo fundamental é a definição de funções. Aqui a ideia é que os indivíduos que cruzam a porta de entrada da universidade adotem funções específicas que conferem determinados privilégios e responsabilidades e restringem outros. $\mathrm{O}$ mais óbvio deles é a diferenciação entre aqueles que ensinam e aqueles que aprendem. Embora a diferenciação entre ensinar e aprender possa ser quase universal, a profissionalização e a fossilização destas funções não é: em alguns contextos culturais e institucionais, as pessoas podem se deslocar entre estas funções em diferentes pontos do tempo e dependendo da forma de atividade. Conforme foi discutido acima, Illich critica a noção de professor como especialista, não porque exista qualquer coisa de errado com o ensinar, mas porque é problemático quando um indivíduo é permanentemente profissionalizado como professor e, com isso, retira a função docente de outros.

Nas universidades, as funções são razoavelmente bem definidas: professores catedráticos/professores assistentes por um lado e, por outro, estudantes, com diferentes posições na sala de aula, diferentes tempos para falar e escutar, diferentes níveis de controle sobre o currículo e as formas de ensino, diferentes espaços de lazer e diferentes relações financeiras com a instituição (um recebendo e o outro pagando ou sendo pago). Fundamentalmente, os professores decidem sobre o programa de estudos, enquanto os estudantes têm apenas um limitado arbítrio sobre o que aprendem: embora na maior parte dos sistemas tenham escolhido seu curso, e em determinada combinação de módulos, é raro que tenham definido o conteúdo, a sequência ou as formas de avaliação.

Também existem formas mais sutis de diferenciação nestas categorias gerais: assim, há diferentes níveis de estudantes, da graduação ao nível de mestrado e doutorado - sendo que, em algumas instituições, os pesquisadores de doutorado têm um papel limítrofe entre estudantes e corpo docente; entre diferentes classes de professor assistente/professor catedrático e corpo docente temporário; e entre o corpo acadêmico e não acadêmico. Até aqui falamos apenas de diferenciações de função, mas elas são inevitavelmente acompanhadas por hierarquias - de prestígio e de poder. A mais óbvia é estes cargos serem assumidos por titulares de cargos superiores na universidade - Reitor, Pró-Reitores, diretores de faculdades e assim por diante - embora tanto o prestígio como 
o poder nas universidades possam ser assumidos por aqueles que não estejam em funções gerenciais.

Dentro da noção de funções, também podemos incluir afiliações disciplinares, conforme foi analisado no trabalho sobre tribos e territórios acadêmicos (Becher; Trowler, 2001). Além de professores catedráticos ou assistentes, o corpo docente também é formado por historiadores de arte, físicos etc., e suas atividades e relações dependem fortemente destas identidades disciplinares. Essas divisões levantam questões mais amplas sobre a natureza e a estrutura do conhecimento que não podem ser abrangidas completamente neste artigo. Com relação aos grandes desafios enfrentados pela humanidade no século XXI, e especificamente aqueles referentes ao desenvolvimento sustentável e à mudança climática, muitos têm discutido que a especialização disciplinar - embora tenha gerado frutos extraordinários - faz parte do problema e que precisamos rumar para o trabalho inter e transdisciplinar (Unesco, 2021).

A função atribuída ao docente também envolve ser o juiz daquilo que os estudantes devem aprender e o curador do programa de estudos. A estruturação do currículo foi extensamente estudada na sociologia da educação: por exemplo, Bernstein (1973) descreveu em termos de classificação as maneiras como o conhecimento é dividido em diferentes áreas, e a força dos limites entre elas, e de enquadramento do controle sobre o que está ou não dentro daquela área, a apresentação desse conhecimento no ato pedagógico. O currículo pode tender para um código em coletânea (com um relacionamento fechado entre áreas de conhecimento) ou um código integrado (com uma relação aberta), e as pedagogias podem ser mais ou menos visíveis (enquadramento forte) ou invisíveis (enquadramento fraco). Estas ideias são importantes ao destacar que a diferenciação de funções e de controle de processos educacionais pode ocorrer de maneiras sutis, mesmo em pedagogias progressistas em que, ao olhar externo, o docente está mais em segundo plano, na função de facilitador, e os estudantes são mais ativos e empoderados no contexto da sala de aula. Também existe a questão - levantada por Bernstein (1974) com relação às pedagogias visíveis e invisíveis, e à vantagem relativa das classes médias para navegar os espaços educacionais sem classificação e enquadramento fortes - aqueles em que a abertura de espaços de aprendizagem desescolarizados pode tornar a aprendizagem mais difícil para estudantes desfavorecidos.

As implicações da função do docente como curador do conhecimento são, portanto, complexas. Quando os estudantes na cidade de Bolonha no século XI formaram uma associação para contratar professores, e no processo criaram a primeira universidade europeia, tinham claras razões para fazê-lo. Havia áreas de conhecimento nas quais queriam ser proficientes (direito, teologia) e consideravam os professores como a maneira mais apropriada para aquisição de informações e que, por meio deles, conseguiriam adquirir a validação do conhecimento (carimbos). Todas estas são motivações razoáveis e embasaram o surgimento do docente profissional em quase todos os contextos do mundo em todos os níveis do sistema educacional. 
Desinstitucionalização e Renovação no Ensino Superior

No entanto, existe outro lado nesta história. Conforme Illich indicou, embora possamos procurar aprender com aqueles mais experientes ou informados do que nós, estas pessoas não precisam ser docentes profissionais e podemos, alternativamente, assumir a função de professor e estudante em diferentes situações, dependendo do contexto e do campo do conhecimento. A existência de professores como especialistas pode ser incapacitante e pode incentivar as pessoas a abandonarem a aprendizagem com professores não profissionais, com outros estudantes e por si mesmos.

Especificamente com relação à universidade, a aprendizagem autônoma é comum, e a dependência dos docentes é muito menor do que em níveis inferiores do sistema educacional. No entanto, o foco primário ainda está na sala de aula, no currículo formal e no professor, e pode levar a uma negligência lamentável de outros espaços de aprendizagem na universidade. De fato, ocorre uma aprendizagem muito significativa - do tipo acadêmico e não acadêmico - em outros espaços: na biblioteca, na cafeteria, caminhando até a parada de ônibus, sem mencionar as atividades no campus e nas associações estudantis e a aprendizagem experiencial além da universidade. $\mathrm{O}$ foco no docente também pode levar a uma desvalorização da aprendizagem coletiva entre os estudantes.

É verdade que, em comparação com outras instituições educacionais, a universidade é relativamente fluida em termos de suas funções. Os uniformes não são comuns, exceto o uso ocasional de emblemas na roupa, declarando o orgulho pela afiliação ou talento esportivo. Embora exista uma significativa variação entre contextos culturais, há menos diferenciação e formalidade nas relações entre estudantes e funcionários do que nas escolas - ajudada pelo fato de todos serem adultos. Entre os funcionários, embora haja hierarquias substanciais de prestígio, os níveis de controle são mais baixos do que em muitas formas de organização, e existe um grau substancial de autonomia de trabalho. No entanto, apesar desta relativa fluidez, a instituição ainda é caracterizada pela diferenciação: um complexo rol de designações e funções que separam as pessoas e demarcam como supostamente deveriam agir e ser tratadas. Por outro lado, as experiências de desescolarização tendem a se caracterizar por um relaxamento desta diferenciação e por funções mais fluidas.

\section{Carimbos}

O terceiro destes elementos é a validação. Um dos poderes básicos da universidade é conferir aos indivíduos um selo de legitimidade de seu conhecimento, compreensão e prática em determinado campo de estudo, e muitas vezes de licença para exercer uma profissão. Tais carimbos se tornaram fundamentais para o funcionamento da sociedade por seu uso como indicadores para os empregadores em suas práticas de recrutamento, seja denotando habilidades em determinada área do trabalho ou atributos genéricos de conhecimento, habilidade e aplicação. Em alguns casos, os órgãos profissionais exercem seu próprio controle sobre 
o ingresso em uma profissão, mas muitas vezes esta tarefa é totalmente entregue ao sistema de ensino superior. A validação da aprendizagem, e particularmente a aprendizagem profissional, tornou o ensino superior quase uma necessidade para aqueles com privilégios suficientes para acessá-lo, e sem dúvida tem sido a causa principal da impressionante taxa de expansão nos últimos cinquenta anos (Marginson, 2016).

A segunda área de validação importante é o conhecimento coletivo na forma de produtos acadêmicos. Embora em muitos países as editoras acadêmicas sejam independentes das universidades, com o processo de revisão por pares é fundamentalmente o corpo docente que confere o carimbo de legitimidade da pesquisa publicada. Embora existam muitas formas de publicação acadêmica, e nos campos das artes e das humanidades os livros sejam fundamentais, é o artigo em periódico científico que representa o padrão ouro. Por meio dos processos de revisão de periódicos, as universidades determinam qual pesquisa e conhecimento adquirido tem o rigor, a originalidade e a importância necessária para assumir seu lugar na literatura do campo.

Os carimbos são uma boa ilustração dos problemas de institucionalização de maneira geral. Começam como um mecanismo bemintencionado para certificar o conhecimento: a avaliação durante a experiência de aprendizagem pode servir a um propósito formativo ao orientar a docência, e ao fim oferecer confirmação do nível de competência do estudante e da conclusão bem-sucedida do curso. Entretanto, a importância da certificação final em termos de futuras oportunidades aos estudantes significa que é a avaliação e não o processo de aprendizagem que se torna, no fim, o ponto focal mais importante. Esta sobreênfase de atenção leva àquilo que foi chamado de 'o rabo abanando o cachorro', em que, em vez de avaliações seguindo-se à aprendizagem, elas terminam por determinar o processo de aprendizagem. Esta dinâmica é observada em todos os níveis do sistema educacional. Esta tendência pode terminar corrompendo a missão de todo o sistema educacional, como foi analisado por Dore (1976) em seu trabalho sobre a doença do diploma em diversos países.

Os carimbos relacionadas à validação do conhecimento acadêmico também podem mostrar sinais do rabo abanando o cachorro. Ao invés de o corpo docente procurar compreender e então publicar em benefício de outrem, as metas terminam sendo os próprios produtos, sendo a pesquisa orientada para maximizar sua quantidade e prestígio. Estas tendências estão associadas com as ideias mais gerais de performatividade no contexto do neoliberalismo (Ball, 2012) e no ensino superior, aumentando o uso de sistemas de avaliação para pesquisadores e de métricas associadas a citações em periódicos. Além disso, existe uma dimensão homogeneizadora na avaliação de produtos quando a maior parte dos periódicos de alto prestígio listados na Web of Science é publicada em língua inglesa e localizada em países de alta renda.

Portanto, as discussões sobre publicação acadêmica demonstram as íntimas ligações entre desinstitucionalização e decolonização: o sistema de carimbos (neste caso, a indústria editorial acadêmica global) 
Desinstitucionalização e Renovação no Ensino Superior

atua para reforçar o controle hegemônico do Norte global por meio dos (frequentemente tácitos) códigos e critérios de aceitação de artigos, dificultando que outras vozes e epistemologias alternativas sejam expostas. Com isso, rumar para uma ecologia de conhecimentos e pluralismo epistêmico (Santos, 2015; Arora; Stirling, 2020) exige que analisemos estruturas institucionais e interinstitucionais de validação.

Este ponto nos leva a outra crítica fundamental do conhecimento acadêmico convencional em sua individualização. Os sistemas de educação superior e as comunidades acadêmicas se alimentam de narcisismo, com egos constantemente estufados ou esvaziados pelo reconhecimento ou rejeição das ideias propostas. Mesmo assim, conforme argumenta Ashwin (2016), a propriedade individual das ideias é um tanto ilusória, e apesar de muito do que imaginamos ser uma contribuição original, foi inevitavelmente construída por esforços coletivos da comunidade acadêmica e pensadores anteriores. Esta exclusividade pode ser considerada como uma barreira tão grande quanto as limitações comerciais sobre a propriedade intelectual (Unesco, 2021). A individualização da autoria pode ser ilusória, conforme foi discutido acima, mas também pode ser indesejável, com benefícios consideráveis a serem obtidos por meio da liberação gratuita, como é discutido extensamente com relação ao software Linux, por exemplo. Assim, embora haja claros benefícios para o sistema de revisão por pares, pode servir para reproduzir uma única história, uma determinada maneira de saber e marginalizar outras.

Com base em processos de validação da produção de aprendizagem e conhecimento, podemos ver instituições como um todo obtendo carimbos - pelo reconhecimento conferido por ranqueamentos universitários, sendo os mais proeminentes o ranqueamento Shanghai, o Times Higher Education e o QS em nível internacional, mas também uma série de ranqueamentos em nível nacional. Além de desviar a missão e as atividades das universidades para pesquisa e publicações de elite, outro impacto dos ranqueamentos (e, na verdade, de todas as formas de carimbos) está em promover a competição ao invés da colaboração - levando ao que Naidoo (2018) chama de fetichização destas relações competitivas.

Até aqui a análise abordou estes três elementos em separado, mas claramente existem conexões entre eles. As portas de entrada funcionam em relação a funções específicas - as pessoas são selecionadas para se adaptarem ao molde do estudante de graduação, professor ingressante e assim por diante. As portas de entrada também se abrem ou fecham em relação aos carimbos: parte da função da seletividade em uma instituição é restringir o acesso àquelas pessoas que provavelmente irão obter o carimbo e assegurar que o reconhecimento não seja distribuído de maneira ampla demais e, com isso, perca seu valor posicional. O movimento entre funções também depende da aquisição de carimbos. Em suma, existem numerosas maneiras pelas quais os três interagem para modificar uns aos outros. 
Esta seção identificou algumas características evidentes da instituição universidade, na maneira como regula sua atividade interna e se relaciona com o mundo externo. Assumiu como ponto de partida que existe um alto grau de homogeneidade e de pressupostos fundamentais compartilhados sobre a instituição. No entanto, deve-se reconhecer que existe diversidade entre contextos (cultural, por nível de recursos) e entre tipos institucionais (universidade com pesquisa intensiva, instituição de ensino apenas, universidade aberta em meio virtual) na maneira como estas três características se manifestam. Embora apareçam em todas as instituições, há diversidade em relação a três elementos:

a. Forma - natureza da estrutura: por exemplo, que tipo de diplomas são emitidos

b. Controle- lócus de tomada de decisão: por exemplo, quem define a política de admissão

c. Rigidez - grau de firmeza ou flexibilidade: por exemplo, qual a fluidez das funções na universidade

O impacto das estruturas institucionais na prática depende em grande medida de sua forma, controle e rigidez. Entretanto, apesar desta diversidade, podemos observar algumas tendências gerais nos sistemas de ensino superior. O que pode ser claramente observado é uma ilustração da tese de Illich de que as formas institucionais começam de maneira bem-intencionada, mas tendem a abusar da acolhida e se tornam corruptas. As portas de entrada começam como uma maneira de assegurar a adequação dos estudantes e a viabilidade de recursos, mas terminam sendo um mecanismo para exclusão e gestão de marca. As funções permitem os benefícios da especialização, mas podem sufocar e incapacitar. No começo, os carimbos são uma maneira de reconhecer o que foi realizado, mas começam a dominar o processo, determinando (e empobrecendo) o que vier antes. A seção a seguir apresenta dois relatos breves de duas iniciativas que tentaram subverter estas estruturas para evitar estes impactos negativos e recuperar o espírito da universidade.

\section{Desinstitucionalizando a universidade}

A Unitierra (ou Universidad de la Tierra, Universidade da Terra) foi fundada em Oaxaca, México em 1999 e continua presente lá, além de ter ramificações em Chiapas, Puebla e na Califórnia. Foi criada por insatisfação de grupos indígenas e outros grupos da comunidade local com a educação convencional e um desejo de criar uma oferta de baixo para cima, livre da dependência do estado ou do mercado. Está embasada em práticas indígenas tradicionais, com ligações com os zapatistas, bem como com as ideias do pensador do pós-desenvolvimento Gustavo Esteva, que foi um dos membros fundadores. A declaração a seguir resume a missão fundante:

A Universidad de la Tierra, ou Unitierra, nasceu então entre o contexto de reações radicais contra a escolarização 
Desinstitucionalização e Renovação no Ensino Superior

observada em muitas comunidades indígenas. Chamamo-nos de Universidade para reivindicar a antiga tradição das primeiras universidades: aprender com os amigos em torno de uma mesa pelo único prazer de aprender e pela paixão que o estudo inspira. Nossa universidade não é para obter um diploma ou ascender na pirâmide educacional. Recebemos jovens com e sem certificado de conclusão; alguns deles têm educação formal, enquanto outros nunca foram à escola (Unitierra, s.d.).

A universidade funciona essencialmente por livre associação de educandos em um modelo de estágios, além de grupos de estudo coletivo, tanto acerca de temas gerais como específicos. É fundamentalmente apoiada por doações e é governada por uma assembleia participativa.

A Universidade Swaraj compartilha várias características com a Unitierra, e há muitos pontos de contato entre as ideias de seu fundador, Manish Jain, e de Gustavo Esteva. Foi fundada em 2010 perto de Udaipur, norte da Índia, para oferecer programas educacionais alternativos para jovens com base na aprendizagem auto desenhada. Os estudantes - conhecidos como Khojis, aqueles que procuram - cursam um programa de dois anos construindo seu próprio currículo de acordo com seus próprios interesses, inseridos em uma comunidade de aprendizagem. As áreas curriculares incluem o seguinte: design e arquitetura, alimento e agricultura, arte e história, espiritualidade, cura e autocuidado, empreendedorismo, ciência e ambiente. Assim como a Unitierra, a Swaraj combina mentoria (neste caso baseada na tradição hindu gurushishya) tanto para desenvolvimento baseado em habilidades como em sabedoria por meio de aprendizagem coletiva em grupo. Sua oposição à certificação é explícita:

\begin{abstract}
A Universidade Swaraj não exige NENHUMA comprovação ou certificação para ingresso e não realizamos colação de grau após o curso. Temos orgulho em sermos totalmente não reconhecidos e não considerados, pois acreditamos na criação de portfólios com base na experiência própria em vez de graduação e certificação como prova da educação de alguém. Também fazemos parte da campanha $\mathrm{He}$ aling Ourselves from the Diploma Disease [Curando-nos da Doença do Diploma], uma campanha nacional para dizer NÃO a graduações e certificados e promover uma melhor estrutura de avaliação, como aquela embasada em experiência e portfólios (Swaraj University, s.d.).
\end{abstract}

No entanto, existe uma referência ao reconhecimento público, pois a organização identificou uma gama de empregadores dispostos a reconhecer os portfólios desenvolvidos pelos educandos.

Estas duas iniciativas foram selecionadas entre as experiências alternativas de educação superior mais profundamente radicais atualmente em andamento. Também compartilham muitas características e serão majoritariamente abordadas em conjunto na análise que segue. É importante indicar que esta não é uma análise de seu impacto na prá- 
tica (o que exigiria uma pesquisa empírica detalhada), mas uma avaliação do desafio ao modelo teórico da universidade.

É claro que ambas as iniciativas representam profundos desafios à nossa concepção de 'universidade' e às três características esboçadas acima. Primeiro, as portas de entrada são significativamente reduzidas e modificadas. Não é feita nenhuma seleção com base no mérito acadêmico e não é cobrada nenhuma taxa para admissão. As únicas restrições (no caso da Unitierra) são ser adulto e ter uma proposta de estudo e engajamento comunitário. Naturalmente, existem diversas barreiras pessoais que podem impedir que os indivíduos se apresentem como estudantes (carência de tempo, falta de confiança e assim por diante), mas quase nenhum controle institucional.

As funções também são fluidas neste modelo. Embora haja pessoas com um compromisso continuado com a instituição que poderiam corresponder a membros do corpo docente e que assegurem a continuidade da iniciativa, não são professores profissionais e, às vezes, também têm a função de educandos. É importante mencionar que as funções de professor e estudante são reversíveis. Em uma situação, alguém pode estar fazendo mentoria com outro na realização de documentários e, em outro caso, receber mentoria dele em filosofia grega antiga.

No caso dos carimbos, talvez as mudanças sejam as mais radicais. As instituições não fornecem nenhuma certificação para o aprendizado adquirido - nem do tipo 'graduação' formal reconhecido publicamente, nem do estilo de microcredenciamento que está se popularizando na aprendizagem virtual. Esta é uma estratégia deliberada para resgatar a aprendizagem da tirania das qualificações. Como estas instituições não têm obrigação com nenhum órgão ou julgamento externo, estão livres de ter que orientar suas atividades para as expectativas profissionais ou outras, e abrem espaço para a aprendizagem orgânica.

É importante enfatizar, entretanto, que é impossível se livrar inteiramente destas estruturas. Podem ser enfraquecidas ou tornadas menos significativas ou ser reorientadas, mas ainda assim estarão lá em algum grau. Uma experiência educacional inteiramente sem estrutura é impossível - sobretudo porque, por definição, a educação sempre tem um elemento de intencionalidade. A aprendizagem pode ocorrer em qualquer momento na vida, mas é educação apenas quando a experiência de aprendizagem for deliberadamente organizada. No entanto, existem marcadas diferenças na extensão e no impacto destas estruturas, tornando significativo falar sobre maiores ou menores níveis de institucionalização.

Portanto, portas de entrada, funções e carimbos não são completamente erradicadas nestas iniciativas, mas são profundamente transformadas. Com relação às três características esboçadas acima: sua forma é alterada - no exemplo de Swaraj, os carimbos se transformam em um portfólio de trabalho substancial ao invés de um certificado; o lócus de controle muda - sua composição é determinada pelo indivíduo educando em colaboração com pares; e a rigidez é diminuída - com extensa 
Desinstitucionalização e Renovação no Ensino Superior

flexibilidade no modo como o portfólio é construído e sem obrigação alguma de criá-lo.

Ao avaliar estas inovações, é importante ter em mente que os processos de desinstitucionalização são dinâmicos. Não é uma tarefa pontual de remover ou transformar estruturas, pois a tendência natural é que as estruturas cresçam e se ossifiquem com o tempo, tornando-se tão difíceis de manejar quanto aquelas que substituíram. Portanto, é necessário verificar constantemente se os aparelhos institucionais estão apoiando ou expulsando as finalidades centrais.

As profundas mudanças nestes elementos podem nos levar a questionar se o que estamos tratando de fato aqui é uma universidade ou uma instituição de ensino superior de verdade. Contudo, de acordo com os critérios discutidos anteriormente - o objetivo de promover a compreensão humana por meio da pesquisa aberta e em profundidade -, não há dúvida de que estas iniciativas estão vestindo a carapuça. E, embora seja necessário um estudo empírico adicional para compreender inteiramente o impacto na prática, estão fazendo-o de muitos modos e de maneira revigorada para segmentos da população que são rotineiramente excluídos das instituições convencionais de ensino superior.

É importante não confundir a orientação específica destas duas instituições (e outras como elas) com o desafio que fazem à instituição. O que ocorre é que ambas estão orientadas para a inclusividade social, conhecimento indígena e sustentabilidade ambiental; com isso, muitas de suas atividades da área giram em torno destas finalidades. Mas seria possível ter a universidade desescolarizada que enfocava o conhecimento científico, o empreendedorismo, o crescimento espiritual ou a conscientização política. Será que isto seria indistinguível de uma sociedade erudita, ou um grupo de leitura, ou um grupo de amigos e colegas que se apoiam mutuamente em seus estudos? Ou talvez seja estas diferenciações que precisamos desafiar.

Naturalmente, com transformações tão profundas quanto estas, existem perdas em potencial, bem como ganhos. Conforme foi esboçado em um estudo anterior (McCowan, 2016), a educação superior radical sofre significativamente com a falta de reconhecimento proporcionado por qualificações, lutando assim para angariar tanto recursos como estudantes. Este ponto consubstancia a ideia de Illich do ciclo de perpetuação: a sociedade está tão impregnada da estrutura das qualificações que escapar dela significa arriscar quase tudo, e a maioria das pessoas não está disposta a fazer esta aposta. A situação irá mudar quando houver uma massa crítica de pessoas optando por não receber diplomas convencionais, mas esse tempo está um pouco distante.

Optar por não receber carimbos pode, de fato, impactar a abertura das portas de entrada. Na prática, dada a necessidade de qualificações formais para as oportunidades profissionais mais compensadoras e bem remuneradas na sociedade, a maioria dos jovens não tem (ou não sente que tenha) a opção de frequentar uma instituição deste tipo. Con- 
sequentemente, aqueles que frequentam estas instituições terminam sendo aqueles que já têm qualificações formais, aqueles que têm segurança financeira e, portanto, não precisam delas, ou aqueles que não têm nenhuma possibilidade de obtê-las. Portanto, até que ocorra uma importante mudança na sociedade, o risco de optar por não ingressar no setor de emprego convencional é simplesmente alto demais para muitas pessoas, particularmente aquelas sem segurança financeira.

Um problema diametralmente oposto representado pela falta de portas de entrada é o potencial de afluência de estudantes. Em parte, as portas de entrada estão lá para assegurar que a entrada não exceda o recurso disponível. Até o momento, isso não é um problema na Swaraj e na Unitierra porque a falta de reconhecimento público significa que a captação em grande escala entre a população geral é improvável. Mas um aumento de demanda no futuro pressionaria a capacidade da instituição de manter uma porta de entrada aberta. Ademais, as portas de entrada atendem à finalidade de selecionar aqueles estudantes que possam aproveitar as oportunidades de aprendizagem: assim, na maioria dos casos, as universidades exigem que os estudantes já tenham competências e habilidades básicas para se envolverem de maneira significativa com o material. Ter que oferecer a instrução básica além da aprendizagem em profundidade especializada característica da universidade pode impor uma significativa pressão sobre a viabilidade da instituição.

As futuras instituições imaginadas por Stanley (2019) - como a Platform University e o Microcollege- abordam estes problemas práticos ao contar com estruturas orgânicas pelas quais estes encontros pedagógicos podem sofrer ascensão e queda ao longo do tempo, levantando e alocando seus próprios fundos, enquanto a plataforma continua como um centro estável no qual esta interação pode ocorrer. Entretanto, não está claro qual a facilidade para este modelo ser implementado na prática, particularmente em contextos de recursos limitados, e sem comercialização do empreendimento. Os desafios de buscar recursos e reconhecimento público não são triviais e dissuadem a maioria dos inovadores de criar suas experiências de ensino superior inteiramente fora do sistema convencional. No entanto, a análise acima mostra o nível de ruptura que pode ser alcançado quando uma iniciativa não está amarrada a estruturas legais, políticas, financeiras e de acreditação. Apesar de, na prática, os impactos exigirem pesquisa empírica adicional, sua função como uma referência de possibilidade e um instrumento para libertar a imaginação é inegável.

\section{Direções futuras}

Portanto, ao reformar a universidade, precisamos olhar para além dos ajustes superficiais em sistemas e instituições e chegar às estruturas mais profundas que determinam as práticas da instituição e sua relação com a sociedade. Os esforços para decolonizar o currículo, construir um corpo docente e discente representativo e transformar as 
Desinstitucionalização e Renovação no Ensino Superior

universidades para a sustentabilidade somente irão gerar frutos se, ao mesmo tempo, prestarmos atenção para a natureza da instituição e a necessidade de desafiar sua lógica subjacente.

Ao reavaliar a natureza institucional da universidade, é importante ter em mente que mesmo os exemplos convencionais hegemônicos têm enquadramentos bastante frouxos em muitos aspectos. Existe um fraco controle sobre os membros do corpo docente; por exemplo, é comum que seus integrantes critiquem publicamente suas próprias instituições e existe pouca expectativa de seguirem uma 'linha partidária’: quando docentes ou estudantes falam em público, a menos que exerçam funções específicas, em geral se compreende que estão expressando sua própria opinião, não a da instituição. Além disso, a gestão hierárquica funciona apenas em determinadas áreas da universidade ou com relação a determinadas dimensões do trabalho, com substancial liberdade para trabalhar objetivos e padrões entre os docentes (Haddock-Fraser; Rands; Scoffham, 2018).

Foram trazidas à instituição mudanças significativas, em linha com as políticas neoliberais e o capitalismo acadêmico. Novas formas de gestão corporativa vêm tentando controlar e regular a autonomia e a criatividade orgânica representadas acima. Por outro lado, a comodificação e a mercantilização afrouxaram de algumas maneiras o controle institucional ao vincular as universidades a mercados capitalistas de novos modos. As universidades com fins lucrativos, por exemplo, que passaram por rápida expansão nos últimos anos, possuem uma porta de entrada muito ampla em termos de admissões, comumente aceitando todos os estudantes dispostos a pagar as taxas e tendo concluído o ensino médio. A geração de renda também incentiva as universidades a se engajarem de maneiras mais fluidas com as comunidades externas e, particularmente, o setor privado, e alguns dos movimentos rumo ao trabalho interdisciplinar e reestruturação de identidades departamentais e acadêmicas também têm sido orientados por motivações comerciais.

A desagregação (unbundling), facilmente confundida com desescolarização ou desinstitucionalização, está intimamente ligada a estes processos de comodificação. O processo de desagregar (conforme foi examinado em McCowan, 2017; Ivancheva et al., 2020; Robertson; Komljenovic, 2016) também leva a desvendar estruturas convencionais da instituição, porém de maneiras diferentes, com distintas motivações e implicações. Desagregar envolve a separação dos elementos constituintes da universidade e do processo de ensino superior: isto é, ensino, pesquisa e inovação, ou design, oferta e avaliação de cursos. Com certeza apresenta desafios às portas de entrada, funções e carimbos tradicionais: em relação aos últimos, por exemplo, com microcredenciamentos que começam a desafiar as graduações compostas tradicionais (Craig, 2015). A motivação fundamental para esta separação é comercial: oferecer aos consumidores mais opções para aquilo que adquirem e, em alguns casos, especialização e economia de escala a partir do ponto de vista do fornecedor. Uma experiência de ensino superior inteiramente 
desagregada consiste em um rol de experiências de aprendizagem que os estudantes podem escolher livremente, compondo seu perfil único de aprendizagem, e buscando microcredenciamentos nas diferentes áreas, quando apropriado.

Embora tanto a desagregação quanto a desescolarização levem ao fim da universidade como a conhecemos, as questões anteriores resolvem apenas alguns pressupostos de nossas instituições convencionais: embora ofereçam maior liberdade de escolha ao educando, estão baseadas em grande medida em um modelo de pedagogia da transmissão, sendo os educandos receptáculos, e dependem de avaliação e credenciamentos que tenham valor de troca. Além disso, em comparação com a desescolarização de Illich, consideram o propósito da educação como ampliar o sucesso individual em um mercado capitalista, tanto ao vender a empregabilidade de alguém como ao criar produtos inovadores. Embora as barreiras ao acesso sejam desafiadas e haja uma significativa abertura à participação (observada na forma mais extrema pelo surgimento de MOOCs [Massive Open Online Courses]), muitos outros aspectos dos processos institucionais continuam largamente intactos, mesmo com aparência diferente. Portanto, as iniciativas de desinstitucionalização no ensino superior precisam se posicionar em oposição tanto ao ensino superior convencional como às iniciativas de desescolarização comercialmente orientadas.

Este artigo não está, de fato, discutindo que a universidade convencional é inerentemente falha como instituição. Sem dúvida, tem enfrentado muitas influências perniciosas das diferentes eras em que existiu - e no momento contemporâneo, do capitalismo global - e tem um registro misto acerca da promoção do bem público, da igualdade e da sustentabilidade ambiental. Mas está longe das piores instituições contemporâneas nossas e ainda oferece oportunidades para pensamento crítico, visões alternativas e transformação pessoal e coletiva. A questão aqui é que precisa ser criado espaço para o surgimento de novas instituições de ensino superior ao lado da universidade, com diferenças não em ornamentos de superfície, mas nos pressupostos profundos e nas práticas fundamentais.

Illich pode ter sido demasiadamente áspero com a escola. Como uma instituição que tem diversos atributos positivos, oferece algumas oportunidades para aprendizagem significativa mesmo em circunstâncias difíceis no mundo inteiro e para as comunidades em maior desvantagem. No entanto, sua tese fundamental de que, com o tempo, a institucionalização corrompe seu propósito original continua intacta. As estruturas originalmente colocadas em prática para apoiar o funcionamento da instituição - conceituadas como portas de entrada, funções e carimbos - solapam de muitas maneiras esse propósito. Vale ressaltar que confundem a própria finalidade: assim, é a obtenção de uma vaga em Harvard e a obtenção de qualificação de MBA que tem valor, não a experiência e a transformação pessoal em si.

Se as experiências de desinstitucionalização esboçadas aqui forem compreendidas, isso levará à desacomodação de sistemas de ensino 
Desinstitucionalização e Renovação no Ensino Superior

superior - e muito provavelmente à redução dos recursos disponíveis, pois indivíduos, corporações e estados as consideram instrumentalmente menos valiosas para o alcance de diversas metas, fundamentalmente econômicas. Porém, o tamanho e a importância do sistema de ensino superior não são nossa única preocupação. Melhor uma pequena rede de universidades fiel a sua missão e com um impacto positivo na sociedade do que uma grande sem nada disso. De fato, é possível observar a derrocada das universidades devido a este comprometimento de sua própria missão em busca de expansão e aumento de recursos a todo custo.

Experiências como a Swaraj e a Unitierra nos mostram que é possível subverter e reformular até mesmo as estruturas fundantes da instituição, e ainda preservar seu propósito principal - na verdade, cumprindo-o melhor para as comunidades que foram excluídas das instituições convencionais de ensino superior. O que estas inovações nos oferecem, acima de qualquer coisa, é um impulso para nossa imaginação. Depois de séculos de profundo arraigamento de um modelo educacional dominante, imaginar uma alternativa - uma alternativa real, e não variações de tonalidade - é um desafio significativo. Mas é um desafio que precisamos superar se quisermos manter os propósitos originais da universidade e resolver as crises ambiental e civilizacional que a humanidade enfrenta.

Traduzido por Ananyr Porto Fajardo

Recebido em 1 de junho de 2021 Aprovado em 9 de agosto de 2021

\section{Notas}

1 O uso dos termos institucionalização e desinstitucionalização é frequente na literatura para se referir à internação ou à alta de uma criança ou adulto em ou de uma instituição (hospital psiquiátrico, orfanato, prisão etc.). Portanto, tratam de questões referentes ao lugar onde o indivíduo fica mais bem localizado, se dentro da instituição ou na comunidade. Este artigo não utiliza os termos nesse sentido, mas sim com relação ao desenvolvimento ou à desconstrução de aparelhos institucionais.

2 N. T.: Movimento pela retirada da estátua de Cecil John Rhodes do campus da Universidade da Cidade do Cabo. O monumento era considerado um símbolo do passado opressivo da África do Sul, sob o colonialismo e o apartheid e o movimento se transformou em um protesto geral pela necessidade de transformação das universidades.

\section{Referências}

ACEMOGLU, D. et al. Institutions as fundamental cause of long-run growth. In: AGHION, P.; DURLAND, S. N. (Ed.). Handbook of economic growth. v. 1A. Amsterdam: North Holland Publishing, 2005. P. 386-347. 
ANDERSON-LEVITT K.M. A World Culture of Schooling?. In: ANDERSON-LEVITT, K.M. (Ed.). Local Meanings, Global Schooling. New York: Palgrave Macmillan, 2003.

ARORA, S.; STIRLING, A. Don't save 'the world' - embrace a pluriverse! Steps Centre, Falmer, 24 Oct. 2020. Available at: https://steps-centre.org/blog/dontsave-the-world-embrace-a-pluriverse/. Accessed: 3 July 2021.

ASHWIN, P. 'From a teaching perspective, "impact" looks very different'. Times Higher Education, 21 March, 2016. Available at: https://www.timeshighereducation.com/blog/teaching-perspectiveimpact-looks-very-different. Accessed: 3 May 2018.

BAKER, D.; LETENDRE, G. National differences, global similarities: World culture and the future of schooling. Palo Alto, CA: Stanford University Press, 2005.

BALL, S. J. Performativity, Commodification and Commitment: An I-Spy Guide to the Neoliberal University. British Journal of Educational Studies, London, v. 60, n. 1, p. 17-28, 2012.

BECHER, T.; TROWLER, P. R. Academic tribes and territories: Intellectual enquiry and the cultures of discipline 2. ed. Buckingham: Society for Research into Higher Education, 2001.

BENAVOT, A.; RIDDLE, P. The expansion of primary education, 1870-1940. Sociology of Education, v. 61, n. 3, p. 191-210, 1988.

BERNASCONI, A. Is there a Latin American model of the university? Comparative Education Review, v. 52, n. 1, p. 27-52, 2007.

BERNSTEIN, B. On the Classification and Framing of Educational Knowledge. In: BROWN, R. (Ed.). Knowledge, Education, and Cultural Change: Papers on the Sociology of Education. London: Tavistock, 1973. P. 363-392

CHABВOTT, C. Constructing Education for Development: International Organizations and Education For All. London: Taylor and Francis, 2002.

COLLINI, S. What are Universities for? London: Penguin, 2012.

CONNELL, R. Using southern theory: Decolonizing social thought in theory, research and application. Planning Theory, v. 13, n. 2, p. 210-223, 2014.

CORTINA, R.; EARL, A. Embracing interculturality and Indigenous knowledge in Latin American higher education. Compare: A Journal of Comparative and International Education, Abingdon-on-Thames, v. 51, n. 8, 2020. DOI: 10.1080/03057925.2020.1766350.

CRAIG, R. College disrupted: The great unbundling of higher education. New York, NY: Palgrave Macmillan, 2015.

CROW, M.; DABARS, W. Designing the New American University. Baltimore: Johns Hopkins University Press, 2015.

DEL MONTE, P.; POSHOLI, L. Decolonial perspectives on education and international development. In: MCCOWAN, T.; UNTERHALTER, E. (Ed.). Education and International Development: an Introduction. London: Bloomsbury, 2021.

DIETZ, G. Intercultural universities in Mexico: Empowering indigenous peoples or mainstreaming multiculturalism? Intercultural Education, v. 20, n. 1, p. 1-4, 2009.

DIMAGGIO, P. J.; POWELL. W. W. The iron cage revisited: institutional isomorphism and collective rationality in organizational fields. American Sociological Review, v. 48, p. 147-60, 1983. 
DORE, R. The diploma disease: Education, qualification and development. London: George Allen and Unwin, 1976.

HADDOCK-FRASER, J.; RANDS, P.; SCOFFHAM, S. Leadership for Sustainability in Higher Education. London: Bloomsbury Academic, 2018.

HELETA, S. 'Decolonising higher education: Dismantling epistemic violence and Eurocentrism in South Africa'. Transformation in Higher Education, v. 1, n. 1, p. 1-8, 2016.

ILLICH, I. Deschooling Society. New York: Harper \& Row, 1971.

ILLICH, I. Tools for Conviviality. New York: Harper \& Row, 1973.

ILLICH, I. Medical Nemesis: The expropriation of health. London: Marian Boyars, 1975.

IVANCHEVA, M. P. et al. Conflicting logics of online higher education. British Journal of Sociology of Education, London, 2020. https://doi.org/10.1080/01425 692.2020.1784707.

LAURILLARD, D.; KENNEDY, E. The potential of MOOCs for learning at scale in the Global South. Centre for Global Higher Education, London, n. 31, 2017.

MARGINSON, S. Emerging higher education in the Post-Confucian heritage zone. In: ARAYA, D.; MARBER, P. (Ed.). Higher Education in the Global Age. New York: Routledge, 2014. P. 89-112.

MARGINSON, S. The worldwide trend to high participation higher education: dynamics of social stratification in inclusive systems. Higher Education, n. 72, p. 413-434, 2016.

MASON G. et al. Employability Skills Initiatives in Higher Education: What Effects Do They have on Graduate Labour Market Outcomes? London: National Institute of Economic and Social Research, 2006.

MBEMBE, A. J. Decolonizing the university: New directions. Arts \& Humanities in Higher Education, v. 15, n. 1, p. 29-45, 2016.

MCCOWAN, T. Expansion without equity: an analysis of current policy on access to higher education in Brazil. Higher Education, v. 53, n. 5, p. 579-598, 2007.

MCCOWAN, T. Forging radical alternatives in higher education: the case of Brazil. Other Education, v. 5, n. 2, p. 196-220, 2016.

MCCOWAN, T. Higher education, unbundling and the end of the university as we know it. Oxford Review of Education, v. 43, n. 6, p. 733-748, 2017.

MCCOWAN, T. Higher Education for and beyond the Sustainable Development Goals. London: Palgrave Macmillan, 2019.

MCCOWAN, T; LEAL FILHO, W.; BRANDLI, L. (Ed.). Universities Facing Climate Change and Sustainability. Hamburg: Global University Leaders Council, 2021. MEYER, H.-D.; ROWAN, B. (Ed.). The new institutionalism in education. Albany: State University of New York Press, 2006.

MEYER, J.W. et al. The world educational revolution 1950-1970. Sociology of Education, v. 50, n. 4, p. 242-258, 1977.

MORPHEW, C. C.; HUISMAN, J. Using institutional theory to reframe research on academic drift. Higher Education in Europe, v. 27, n. 4, p. 491-506, 2002.

NAIDOO, R. The competition fetish in higher education: Shamans, mind snares and consequences. European Educational Research Journal, v. 17, n. 5, p. 605$620,2018$. 
NORÕES, K.; COSTA, B. Affirmative Policies in Brazil: Black Movements and Public Higher Education. Educational Thought, v. 9, n. 1, p. 24-31, 2012.

NORTH, D. Institutions, institutional change and economic performance. New York: Cambridge University Press, 1990.

PERALES FRANCO, C.; MCCOWAN, T. Rewiring higher education for the Sustainable Development Goals: the case of the Intercultural University of Veracruz, Mexico. Higher Education, n. 81, p. 69-88, 2021.

REIMER, E. School is Dead. An essay on alternatives in education. Harmondsworth: Penguin, 1971.

ROBERTSON, S. L.; KOMLJENOVIC, J. Unbundling the university and making higher education markets. In: VERGER, A.; LUBIENSKI, C.; STEINER-KAMSI, G. (Ed.). World yearbook in education (Global edu). London: Routledge, 2016.

SANTOS, B. S. Epistemologies of the South: justice against epistemicide. New York: Routledge, 2015.

SANTOS, B. S. Decolonising the University: The Challenge of Deep Cognitive Justice. Newcastle: Cambridge Scholars Publishing, 2017.

SANTOS, B. S. The End of the Cognitive Empire: The Coming of Age of Epistemologies of the South. Durham: Duke University Press, 2018.

SCHMELKES, S. Intercultural universities in Mexico: Progress and difficulties. Intercultural Education, v. 20, n. 1, p. 5-17, 2009.

SCOTT, W. R. Institutions and Organisations: Ideas, Interests and Identities. Thousand Oaks: Sage, 2013.

SILOVA, I.; RAPPLEYE, J. Beyond the world culture debate in comparative education: critiques, alternatives and a noisy conversation. Globalisation, Societies and Education, v. 13, n. 1, p. 1-7, 2015.

SMITH, M. K. 'Ivan Illich: deschooling, conviviality and the possibilities for informal education and lifelong learning'. In: INFED.ORG: EDUCATION, COMMUNITY-BUILDING AND CHANGE. The encyclopedia of pedagogy and informal education. 2011. Available at: http://www.infed.org/thinkers/et-illic.htm. Accessed: 9 May 2020.

STALEY, D. J. Alternative universities: Speculative design for innovation in higher education. Baltimore, MD: Johns Hopkins University Press, 2019.

STENSAKER, B. et al. Stratified university strategies: The shaping of institutional legitimacy in a global perspective. The Journal of Higher Education, London, v. 90 , n. 4, p. 539-562, 2019.

SUKARIEH, M.; TANNOCK, S. Deschooling from above. Race \& Class, p. 1-19, 2020.

TAKAYAMA, K.; SRIPRAKASH, A.; CONNELL, R. Rethinking Knowledge Production and Circulation in Comparative and International Education: Southern Theory, Postcolonial Perspectives, and Alternative Epistemologies. Comparative Education Review, Chicago, v. 59, n. 1, p. v-viii, 2015.

TURNER, J. The Institutional Order. New York: Longman, 1997.

UNESCO. Report of the Global Independent Expert Group on the Universities and the 2030 Agenda. Paris: Unesco, 2021.

UNITIERRA. Universidad de la Tierra. Our History. Oaxaca, n. d. Available at: https://unitierraoax.org/english/. Accessed on: 22 March 2021. 
VÄLIMAA, J. The Nordic idea of university. In: BARNETT, R.; PETERS, M. (Ed.). The idea of the university: contemporary perspectives. New York: Peter Lang, 2018.

WILLIAMSON, B. The hidden architecture of higher education: building a big data infrastructure for the 'smarter university'. International Journal of Educational Technology in Higher Education, Switzerland, v. 15, n. 1, p. 1-26, 2018.

ZAPP, M.; JUNGBLUT, J.; RAMIREZ, F. O. Legitimacy, stratification, and internationalization in global higher education: the case of the International Association of Universities. Tertiary Education and Management, v. 27, n. 1, p. 1-15, 2021.

Tristan McCowan é professor de Educação Internacional no Instituto de Educação, University College London. Seu trabalho enfoca o ensino superior e desenvolvimento internacional. Seu livro mais recente é Higher Education for and beyond the Sustainable Development Goals (Palgrave Macmillan, 2019).

ORCID: https://orcid.org/0000-0002-0710-7519

E-mail: t.mccowan@ucl.ac.uk

Editor-responsável: Luís Armando Gandin

Este é um artigo de acesso aberto distribuído sob os termos de uma Licença Creative Commons Atribuição 4.0 Internacional. Disponível em: <http:// creativecommons.org/licenses/by/4.0>. 